\title{
Política de formação profissional para a educação infantil: Pedagogia e Normal Superior
}

\author{
Tizuko Morchida Kishimoto *
}

\begin{abstract}
RESUMO: O texto trata da política de formação profissional para a educação infantil dos anos 90 configurada pelos cursos de pedagogia e normal superior. A pedagogia historicamente ofereceu a formação em nível superior, desde a década de 1930, demonstrando seu projeto político-pedagógico, ao aliar a licenciatura ao bacharelado, em cursos que formam concomitantemente o professor e o profissional da educação infantil, garantindo um espaço pedagógico de interação entre a formação geral e a profissional. O curso normal superior, recriado pela lei 9394/96, traz uma polêmica ao separar a formação docente da universitária, propor um curso com menor tempo de formação, fragmentar o cuidar do educar e desqualificar o quadro de profissionais responsáveis pelo curso.
\end{abstract}

Palavras-chave: Educação infantil, formação docente, profissionalização, creche, pré-escola

A formação profissional para a educação infantil ressurge com o clima instaurado após a Constituição de 1988, o Estatuto da Criança e do Adolescente, a Lei de Diretrizes e Bases da Educação Nacional e a Lei Orgânica de Assistência Social. Tais dispositivos inserem a criança de 0 a 6 anos no interior do sistema escolar, na educação básica, garantindo o direito da criança à educação e, conseqüentemente, impondo ao Estado a obrigatoriedade de oferecer instituições para essa faixa etária.

* Professora titular e vice-diretora da Faculdade de Educação da Universidade de São Paulo. Docente e pesquisadora na área da educação infantil. Membro da Comissão de Especialistas de Ensino de Pedagogia do SESu/MEC no período de abril de 1998/2000. E-mail: tmkishim@usp.br 
A urgência em integrar o cuidado e a educação, buscando dar continuidade à formação da criança em instituições diversas - como creches, pré-escolas, classes de alfabetização, centros de educação infantil, centros de recreação, casas de infância, entre outras - que convivem neste país continental com profissionais que dispõem, ainda, de precária formação, com grande contingente de leigos, desnuda a premência de reformas institucionais e preparo dos profissionais.

Historicamente essa formação vinha sendo ofertada pelos cursos de pedagogia e o exercício profissional, estendido aos egressos dos cursos de magistério, de nível médio e a leigos.

As estatísticas demonstram a precariedade da formação profissional nesse nível de ensino.

\section{Formação de professores de préescola no Brasil em $1998^{1}$}

\begin{tabular}{|l|c|c|c|c|c|}
\hline $\begin{array}{l}\text { Unidade da } \\
\text { Federação }\end{array}$ & Total & $\begin{array}{c}\text { Fundamental } \\
\text { Incompleto }\end{array}$ & $\begin{array}{c}\text { Fundamental } \\
\text { Completo }\end{array}$ & $\begin{array}{c}\text { Médio } \\
\text { Completo }\end{array}$ & $\begin{array}{c}\text { Superior } \\
\text { Completo }\end{array}$ \\
\hline Brasil & 219.593 & 13.474 & 15.984 & 146.205 & 43.930 \\
\hline$\%$ & $100 \%$ & $6,13 \%$ & $7,27 \%$ & $66,57 \%$ & $20 \%$ \\
\hline
\end{tabular}

Formação de professores em classe de alfabetização $-1998^{2}$

\begin{tabular}{|l|c|c|c|c|c|}
\hline $\begin{array}{l}\text { Unidade da } \\
\text { Federação }\end{array}$ & Total & $\begin{array}{c}\text { Fundamental } \\
\text { Incompleto }\end{array}$ & $\begin{array}{c}\text { Fundamental } \\
\text { Completo }\end{array}$ & $\begin{array}{c}\text { Médio } \\
\text { Completo }\end{array}$ & $\begin{array}{c}\text { Superior } \\
\text { Completo }\end{array}$ \\
\hline Brasil & 46.126 & 7.107 & 6.059 & 28.743 & 4.217 \\
\hline$\%$ & $100 \%$ & $15,4 \%$ & $13,13 \%$ & $62,31 \%$ & $9,14 \%$ \\
\hline
\end{tabular}

Os dados indicam que a grande maioria dos profissionais de préescola e classes de alfabetização já possui nível médio $(66,57 \%$ e $62,31 \%$, respectivamente). Dos professores que atuam nas pré-escolas, $20 \%$ já adquiriram formação superior, enquanto nas classes de alfabetização apenas $9,14 \%$ têm nível superior.

Grande contingente de profissionais com nível médio já pode se candidatar ao ensino superior dentro do processo regular de profissionalização. Os que dispõem apenas de ensino fundamental precisam galgar o ensino médio para dar seqüência à sua profissionalização. A po- 
lítica de formação que visa desativar em pouco tempo o nível médio não prevê a qualificação dos leigos e estará eliminando de $13 \%$ a $18 \%$ dos profissionais de seus postos.

A situação nas creches é mais complicada. O tradicional abandono e descaso, fruto de uma política de exclusão desses profissionais no campo da educação, reflete-se no contingente de leigos que não se pode precisar pela falta de estatísticas. Mesmo nos grandes centros urbanos, a qualificação requerida é, ainda, de ensino fundamental. Há, certamente, um grande contingente que sequer completou o ensino fundamental. Que soluções serão adotadas? Expulsá-los do sistema ou aproveitá-los por meio de programas de qualificação em parceria com organizações diversas? Infelizmente a desativação precoce do magistério de nível médio parece indicar a primeira opção.

A formação de profissionais de educação infantil começa a ser discutida, com maior vigor, neste final de milênio, em virtude das especificações da lei 9394/96, que propõe em seu artigo 87, § $4^{\circ}$ : "Até o final da Década da Educação somente serão admitidos professores habilitados em nível superior ou formados por treinamento em serviço".

Durante a Década da Educação - de 1997 a 2007 -, políticas de formação profissional para a educação básica deverão prever a formação dos quadros docentes em nível superior. Certamente para agilizar essa formação, a mesma lei cria uma nova modalidade de curso - normal superior - que, no interior dos Institutos Superiores de Educação, encarregar-se-ia da formação do profissional de educação infantil.

Regulamentados os Institutos Superiores de Educação, criou-se a polêmica estampada pelo artigo do jornal O Estado de S. Paulo: "Pedagogia não vai mais formar professores" ${ }^{3}$, discutindo o fato de que somente ao normal superior caberia a formação do profissional de educação infantil. Diante desse quadro algumas questões serão discutidas:

Devemos adotar um modelo único de formação profissional ou conviver com a diversidade de propostas no sentido de atender à variabilidade regional?

- A qualidade da formação profissional está sendo garantida concomitantemente à necessidade de expansão dessa formação?

- Há valorização do profissional de educação infantil, com a oferta de uma carreira que permita sua profissionalização, com ascensão na escolaridade? 
- Há respeito pelas novas concepções construídas ao longo da constituição do campo da educação infantil, como o respeito à especificidade da criança de 0 a 6 anos, a integração da educação da criança de 0 a 6 anos ou até 10 anos, a oferta de competências necessárias ao educador no interior do quadro curricular, além da premência em romper práticas tradicionais que separam a teoria da prática?

- A vocação pedagógica do curso de pedagogia aliada à formação docente é um fenômeno recente ou surge desde sua origem atendendo à formação do profissional de educação infantil em nível superior?

- $\quad$ Diante da situação criada pela LDB, com os cursos normais superiores convivendo com a pedagogia, que perspectivas temos para a formação do profissional de educação infantil em nível superior?

Tais questões merecerão destaque nos subtemas:

1. curso de pedagogia e seu projeto pedagógico de formação do professor;

2. a formação do professor de educação infantil no curso normal superior;

3. política de formação do profissional de educação infantil em nível superior.

\section{Ourso de pedagogia e seu projeto pedagógico de formação do professor}

Os estudos sobre o curso de pedagogia geralmente tratam de sua identidade e campo de estudo ${ }^{4}$. Há poucas informações históricas sobre seu aparecimento nos anos 30 , e menos ainda sobre profissionais de educação infantil.

A discussão que envolve os cursos de pedagogia nos tempos atuais trata de sua natureza: se deve formar especialistas ou professores, ou seja, se a pedagogia tem afinidades com ciências da educação e, 
portanto, restringe-se ao aprofundamento de estudos na área ou se envolve também questões de formação docente.

Tem-se aventado que a criação do magistério de educação infantil no interior dos cursos de pedagogia é prática recente e que surge com uma questão levantada nos anos 80: "o que pode mais deve valer para o menos", ou seja, se os egressos do curso de pedagogia podem formar professores de nível médio, para atuar nas séries iniciais do ensino fundamental e educação infantil, porque não podem assumir a docência nessas escolas? Esse fato teria gerado a prática de criar habilitações de séries iniciais e educação infantil no interior dos cursos de pedagogia. Essa ótica tem sido utilizada para justificar a formação profissional para educação infantil nas últimas décadas.

Os dados estatísticos sobre os cursos de formação profissional, em nível superior, colhidos no MEC/SESu/Cosin/Dain, ${ }^{5}$ trazem outros elementos que referendam a vocação histórica do curso de pedagogia que, desde os anos 30, forma professores de educação infantil (pré-escola), como se pode observar pelo quadro 1.

\section{Quadro 1}

Habilitação em educação préescolar em Instituições de Ensino Superior

\begin{tabular}{|l|c|c|c|c|c|c|c|c|c|}
\hline Mantenedor & 1990 & 1980 & 1970 & 1960 & 1950 & 1940 & 1930 & s.d. & Total \\
\hline Estadual & 4 & 5 & 2 & 2 & 1 & - & - & - & 14 \\
\hline Federal & 1 & 4 & 3 & 4 & - & & 2 & 4 & 19 \\
\hline Municipal & 1 & 1 & - & 2 & - & - & - & - & 4 \\
\hline Particular & 14 & 3 & 10 & 4 & 5 & 1 & - & 6 & 43 \\
\hline Total Geral & 20 & 13 & 15 & 12 & 6 & 1 & 2 & 10 & 79 \\
\hline
\end{tabular}

Desde os anos 30, duas universidades já ofereciam cursos em nível superior para profissionais de educação infantil: a Universidade Federal do Rio de Janeiro, com a licenciatura em educação pré-escolar em 1931, e a Universidade Federal do Paraná, em $1938 .{ }^{6}$

Que razões teriam levado duas instituições públicas a instalar cursos, em nível superior, destinados a formar professores de educação infantil? Qual o projeto pedagógico que as orientava?

A aspiração pela formação de professores em nível superior é antiga, pois desde a proclamação da República, a lei estadual $n^{\circ} 88$ previa 
a criação, junto à Escola Normal da capital, em São Paulo, de um curso superior para formar professores de escolas normais e ginásios. Entretanto, foi a criação das faculdades de educação, em 1931, que permitiu a oferta desses cursos. Cabia à Faculdade de Educação a formação universitária geral, concomitante ao preparo do magistério (Chamlian 1996, p. 132).

Na Universidade de São Paulo, criada em 1934, em São Paulo, prevaleceu outra organização, com a instalação da Faculdade de Filosofia, Ciências e Letras, um centro de altos estudos, sem caráter profissional, que dispunha de cursos profissionalizantes que gravitavam a seu redor. Um deles foi o Instituto de Educação, instalado em 1933 e incorporado à Universidade de São Paulo em 1934. Somente em 1938, o Instituto de Educação foi transformado em curso de pedagogia. A Faculdade de Educação só foi instalada posteriormente (idem, ibid.).

Que razões teriam levado os legisladores do passado a abandonar a estrutura proposta pelos Institutos Superiores de Educação e normal superior, para a adoção de cursos de pedagogia, anexos às universidades ou no interior de faculdades de educação? Certamente, ao integrar o bacharelado à licenciatura, configura-se um novo modelo de formação profissional, que unifica a formação universitária e profissionalizante, referendando os cursos de pedagogia no seio das faculdades de educação.

Biarnès (1998), professor titular de ciências da educação da Universidade Paris-Norte justifica a necessidade desse modelo de formação que relaciona a cultura geral à profissional, ou seja, o bacharelado à licenciatura, que propicia diversidade e construção conjunta de saberes entre especialistas e generalistas. Entende que dentro de estruturas universais do pensamento somente a multiplicidade de estratégias de apreensão de saberes, subsidiada pela diversidade do espaço pedagógico, poderá garantir ações criativas e a qualidade do processo ensino-aprendizagem. A interdisciplinaridade das ciências da educação, típica da pedagogia, instala a diversidade necessária ao espaço pedagógico, caracterizando a ligação indissolúvel entre o aprender e o ensinar, referência que não pode ficar ausente do processo de formação profissional (Biarnés 1999, p. 323).

A polêmica reforma da formação de professores na França, ao criar os Institutos Universitários de Formação de Professores (IUFM), estimula governantes brasileiros a instalar um modelo análogo ao francês na forma dos Institutos Superiores de Educação e curso normal superior. Cabe destacar que, mesmo criticado, o modelo francês é superior ao brasileiro, pois permite ao profissional de educação infantil cursar 
três anos no interior de uma universidade, para depois encaminhar-se para o curso profissionalizante (IUFM), por um período de mais dois anos. Entre nós, o futuro profissional já ingressa diretamente de seu curso médio para o profissionalizante (normal superior), sem passar pela universidade, não se beneficiando da diversidade e da pluralidade de formação que caracteriza a cultura universitária.

Idéias gestadas e abandonadas no início deste século são recuperadas pela legislação atual, pela assimilação inadequada de modelos estrangeiros com reflexos na formação profissional.

O contexto atual é bem diverso dos primeiros tempos da República e requer propostas de formação diferenciadas de acordo com o público e as condições presentes. Naquela época, poucas instituições ofereciam cursos para crianças pequenas. $O$ jardim-de-infância anexo à Escola Normal Caetano de Campos, em São Paulo, criado em 1896 como escola-modelo destinada ao estágio, permaneceu modelo de si própria pelo menos durante três décadas pela inexistência de similares (Kishimoto 1988). Nas duas décadas posteriores, instituições públicas e particulares asseguram a formação profissional em nível superior.

A Pontifícia Universidade Católica do Rio Grande do Sul instala em Porto Alegre a licenciatura em educação pré-escolar, em 1942. Nos anos 50 surgem seis cursos similares: Universidade da Região da Campanha em Bagé, RS (1958) e em Santana do Livramento (1958), Universidade de Sorocaba, SP (1955) e Universidade do Sagrado Coração de Bauru, SP (1954), tendo uma única pública, a Universidade Estadual Mesquita Filho - Unesp de Marília (1959).

O aumento dos cursos de formação profissional acompanha a precária expansão da rede de escolas infantis. Nos anos 50 , no estado de São Paulo, as 500 pré-escolas existentes eram fiscalizadas por um serviço pré-primário que não tinha estatuto oficial, composto por um grupo de professores emprestados de outros setores. Nos anos 60 , dobra a oferta de cursos, tendo o governo federal e a iniciativa particular na vanguarda.

A década de 1970 alimenta a discussão ancorada na ideologia da privação cultural, da municipalização da educação infantil, e o setor de educação infantil passa a contar com serviços de controle e fiscalização nas três esferas: federal, estadual e municipal. Esse clima pressiona a formação de profissionais, contribuindo para o aumento no número de cursos, com grande participação da iniciativa privada. 
A explosão das escolas de nível superior mantidas pela iniciativa particular inicia-se nessa década, repercutindo na oferta de 10 cursos destinados à educação pré-escolar. Os anos 80 , a "década perdida", sofrem os efeitos das dificuldades financeiras do país, com intensa recessão econômica, e arrefece a criação de cursos pela iniciativa particular. $O$ setor público, notadamente o estadual e o federal, continua a aumentar a oferta. $O$ crescimento é retomado na década seguinte, com 15 novos cursos sob a responsabilidade de setores privados.

O crescimento significativo na instalação de cursos por parte das universidades federais, à semelhança das estaduais, perde o vigor nos anos 90 . A política de sucateamento das instituições federais e o crescente número de aposentadorias no seio de uma política neoliberal que vem privatizando os serviços públicos certamente constituem fatores que explicam o esvaziamento de instituições públicas e sua incapacidade para manter e gerir novos cursos.

Se é interessante verificar a longevidade dos cursos de formação para a educação infantil, na pedagogia, é extraordinário verificar a presença da habilitação integrada de educação infantil e séries iniciais já nos anos 50 . O quadro 2 registra sua presença ao longo das décadas.

\section{Quadro 2 \\ Habilitação pré-escola à $4^{a}$ série do Ensino Fundamental em Instituições de Ensino Superior}

\begin{tabular}{|l|c|c|c|c|c|c|c|c|c|}
\hline Mantenedor & 1990 & 1980 & 1970 & 1960 & 1950 & 1940 & 1930 & s.d. & Total \\
\hline Estadual & 3 & - & - & 1 & - & - & - & - & 4 \\
\hline Federal & 1 & - & - & 1 & - & - & - & - & 2 \\
\hline Municipal & 11 & - & - & - & - & - & - & - & 11 \\
\hline Particular & 5 & 1 & 2 & - & 3 & - & - & 6 & 17 \\
\hline Total & 20 & 1 & 2 & 2 & 3 & - & - & 6 & 34 \\
\hline
\end{tabular}

O fenômeno da habilitação integrada inicia-se com as discussões para formar conjuntamente professores da antiga escola primária, pré-escola, escola maternal e jardim-de-infância. Desde os anos 30, na época em que poucas instituições formavam o professor de educação infantil, era o Curso Normal, em nível médio, que habilita- 
va o profissional para atuar no ensino primário ( 7 a 10 anos), jardinsde-infância ( 3 a 6 anos), escolas maternais ( 2 a 3 anos), classes préescolares ( 6 anos) anexas a grupos escolares e também nas creches ( 0 a 6 ou até 10 anos ou mais).

Nessa época, embora com justificativas que precisam ser mais bem investigadas e com projetos pedagógicos desconhecidos, já tínhamos o profissional destinado a atuar na faixa etária de 4 a 10 anos.

As pioneiras a oferecer formação em nível superior para a faixa etária de 4 a 10 anos foram as instituições particulares: Universidades Católicas do Paraná (1952) e de Pelotas (1956), Universidade Regional do Noroeste do Estado do Rio Grande do Sul, de ljuí (1957); Universidade Regional do Noroeste do Estado do Rio Grande do Sul, de ljuí (1973), Universidade da Região de Campanha, RS (1974) e Universidade da Amazônia (1980). Entre as públicas, destacam-se a Universidade Estadual de Ponta Grossa, PR (1962) e Universidade Federal de Brasília, DF (1962).

É necessário investigar as razões aventadas para a criação desses cursos para formar profissionais de educação infantil e séries iniciais do ensino fundamental, em nível superior, nessas localidades desde os anos 50 .

O substancial avanço na instalação dessa nova modalidade de curso ocorre na década de 1990, sendo conduzido pelas universidades municipais (11), seguidas pelas particulares (5), depois a estadual (3) e, por último, a federal (1). Nessa década foram criados 20 cursos desse tipo, de um total de 34 . Um terço dos novos cursos ficou sob a responsabilidade dos municípios, demonstrando que a municipalização da educação infantil e do ensino fundamental, processo amplamente divulgado no Brasil, incluiu, também, a formação desses profissionais.

Certamente, as experiências de países nórdicos - nos quais o desenvolvimento infantil, a socialização da criança pequena e as múltiplas relações propiciadas pela diversidade de faixas etárias integram o cuidar e o educar - constituem outros fatores estimulantes para a instalação de tais cursos.

A evolução, ao longo desses 60 anos, dos cursos de formação de professores de pré-escola e habilitação integrada de pré-escola a séries iniciais pode ser sintetizada no quadro 3 : 


\section{Quadro 3}

Total de cursos de pedagogia com licenciatura em educação infantil

\begin{tabular}{|l|r|r|r|r|r|r|r|r|r|}
\hline Mantenedor & 1990 & 1980 & 1970 & 1960 & 1950 & 1940 & 1930 & s.d. & Total \\
\hline Estadual & 7 & 5 & 2 & 3 & 1 & - & - & - & 18 \\
\hline Federal & 2 & 4 & 3 & 5 & - & - & 2 & 4 & 20 \\
\hline Municipal & 12 & 1 & - & 2 & - & - & - & - & 15 \\
\hline Particular & 19 & 3 & 12 & 4 & 8 & 1 & - & 12 & 60 \\
\hline Total & 41 & 13 & 17 & 14 & 9 & 1 & 2 & 16 & 113 \\
\hline
\end{tabular}

Até hoje, foram criados 113 cursos de formação de professores de educação infantil. Nota-se o substancial crescimento dos anos 90 , com 41 cursos, ou seja, um terço do total. Ao longo das décadas, coube à iniciativa privada a oferta de maior quantidade de cursos (60). Entre as oficiais, notase atualmente o vigor das instituições municipais, com 12 cursos novos.

É preciso destacar que esse levantamento não é completo, requer complementações, pois o ano de 1999 ainda está em curso e não consta, no banco de dados utilizado, a nova proposta de formação profissional para a faixa etária de 0 a 10 anos (educação infantil a séries iniciais do ensino fundamental), já em vigor, desde 1999, no curso de pedagogia da Faculdade de Educação da Universidade de São Paulo.

A listagem de cursos do Banco de Dados utilizado menciona sempre licenciatura em magistério do pré-escolar à $4^{a}$ série do $1^{\circ} \mathrm{grau}$, indicando que a faixa etária de 0 a 3 anos ficou marginalizada nesse processo de formação profissional, em analogia às creches que só recentemente foram incorporadas ao setor da educação.

A discussão que acompanha a pedagogia desde os anos 60 , que insiste na falta de identidade do curso, desconhece suas raízes voltadas para a formação docente.

O modelo pedagógico e institucional que integra o bacharelado e a licenciatura pode ser visto desde as origens da instalação desses cursos. As universidades federais e estaduais, desde os anos 30, formavam de modo integrado o licenciado para atuar em alguma modalidade de magistério juntamente com atividades de gestão escolar, como administração escolar, supervisão escolar e orientação educacional.

Desde 11/4/1931, a Universidade Federal do Rio de Janeiro oferecia as licenciaturas em pré-escola, magistério das matérias pedagógicas do 
$2^{\circ}$ grau, juntamente com orientação educacional, supervisão escolar de $1^{\circ}$ e $2^{\circ}$ graus, e administração escolar de $1^{\circ}$ e $2^{\circ}$ graus.

A Universidade de São Paulo oferecia, em 25/1/1934, as licenciaturas em magistério das matérias pedagógicas do $2^{\circ}$ grau e em educação especial, juntamente com orientação educacional de $1^{\circ}$ e $2^{\circ}$ graus, administração escolar de $1^{\circ}$ e $2^{\circ}$ graus e supervisão escolar de $1^{\circ}$ e $2^{\circ}$ graus.

É essa perspectiva que caracteriza o projeto pedagógico do curso de pedagogia, que integra a licenciatura e o bacharelado e define o perfil do pedagogo voltado para ações docentes e outras atividades inerentes ao trabalho pedagógico.

Não se pode dizer que o curso de pedagogia não tem uma identidade. Essa identidade que assegura a formação docente paralelamente às outras funções do campo pedagógico foi construída desde sua origem e reafirmada hoje pelas Diretrizes Curriculares do Curso de Pedagogia, de maio de 1999. A própria LDB, no artigo 67, parágrafo único, referenda esse pressuposto: "A experiência docente é pré-requisito para o exercício profissional de quaisquer outras funções de magistério, nos termos das normas de cada sistema de ensino". A legislação em vigor estabelece que a experiência docente é pré-requisito para qualquer função no magistério, ou seja, sem a experiência docente nenhum especialista em educação pode exercer sua profissão.

\section{A formação do profissional de educação infantil no curso Normal Superior}

Gestada nos primeiros tempos da República, a Escola Normal Superior, por um curto espaço de tempo, formou profissionais para educação infantil e séries iniciais do ensino fundamental, nos Institutos Superiores de Educação, anexos às universidades. O legislador ressuscitou essa modalidade de curso para os tempos atuais, com alterações que merecem ser detalhadas.

A lei 9394/96, em seus artigos 62 e 63, propõe a figura do Instituto Superior de Educação, contendo o curso normal superior destinado a formar professores para a educação infantil e séries iniciais do ensino fundamental. A regulamentação desse curso pelo Conselho Nacional de Educação ocorreu em 10/8/99 e sua homologação em 10/9/99. 
Duas razões são apontadas como justificativas para sua criação:

1) a necessidade de elevar a qualificação dos profissionais dedicados à educação infantil e aos anos iniciais do ensino fundamental, e

2) a dissociação entre teoria e prática. ${ }^{7}$

No que se refere à primeira justificativa, a história demonstra que a qualificação em nível superior já vinha sendo feita desde os anos 30 , pelo curso de pedagogia. Nas últimas décadas, a pedagogia vem sendo reformulada em processo de intensa revisão curricular, procurando ajustar seu projeto pedagógico, tendo em vista atender a padrões de qualidade, e a Associação Nacional pela Formação dos Profissionais da Educação (Anfope) tem conduzido esse movimento nos vários encontros nacionais (Brzezinski 1996).

A criação de uma nova modalidade de curso de formação só se justificaria para ofertar alternativas para o acesso ao ensino superior, divergindo do modelo da pedagogia, de quatro anos, para intensificar a formação nas áreas pouco privilegiadas, dentro de uma política de profissionalização que garanta a continuidade dessa formação. Parece que não é essa a proposta.

O normal superior apresenta um projeto pedagógico com 3200 horas, utilizando adequadamente os dispositivos legais do aproveitamento de estudos. Nesse sentido, ao egresso do curso de magistério, em nível médio, atribui-se 800 horas, como aproveitamento de estudos correlatos. A prática de ensino de 800 horas pode também ser efetuada no próprio local em que o professor trabalha. Logo, são mais 800 horas que são atribuídas ao aluno. Sobram 1600 horas, que podem ser cursadas em dois anos. O normal superior restringe-se, em síntese, a um curso de 1600 horas.

Outra característica que corre em direção contrária à qualidade do ensino é a qualificação exigida para seu corpo docente. Enquanto a pedagogia requer, para que a unidade tenha conceito $\mathrm{A}$, pelo menos $50 \%$ dos docentes com mestrado e doutorado, o normal superior exige apenas $10 \%$ de mestres, o que equivale ao conceito insuficiente para os padrões de qualidade da pedagogia. ${ }^{8}$

O tempo de duração do curso, somado à pouca exigência na contratação do corpo docente, geram conseqüências de várias naturezas: preconceitos, baixos salários, baixa identidade do profissional, poucas expectativas de profissionalização, entre outras.

Hoje, a educação infantil luta para garantir um processo de profissionalização que respeite o acesso ao ensino superior e seu gradual aper- 
feiçoamento, em cursos de especialização e pós-graduação. Ora, o normal superior, análogo às licenciaturas curtas, dificulta o acesso a outros patamares de escolaridade superior.

O curso Normal Superior também não respeita as conquistas efetuadas pelo avanço das discussões no campo da educação infantil: não separar as crianças de 0 a 6 anos em períodos distintos: creches e préescolas, tradição instalada em nosso país e que estimula práticas antigas de fragmentar o cuidar e o educar. Esse pecado é cometido também pela lei 9394/96. O que a Constituição de 1988 conquistou ao referendar a educação da criança de 0 a 6 anos, a lei 9394 anulou, ao separar creche de pré-escola. O normal superior referenda essa fragmentação, adotando a prática dos tempos passados.

A continuidade da educação e da integração das crianças de diferentes faixas etárias são requisitos hoje vistos como fundamentais para o desenvolvimento da criança. As múltiplas relações que podem ser estabelecidas em ambientes educativos nos quais convivem crianças de faixas etárias diversas, juntamente com profissionais de várias áreas, além de pais e membros da comunidade, constituem portas de entrada para a construção do conhecimento que se processa quando se respeita a diversidade social e cultural, a multiplicidade de manifestações da inteligência e a riqueza dos contatos com personagens e situações. Ao respeitar tais pressupostos, a escola infantil do norte da Itália, na região pobre da Reggio Emilia, recebe o título de melhor escola do mundo.

No que se refere à segunda justificativa, a separação teoria e prática parece bem situada, pois os cursos vigentes estão tentando superar essa fragmentação. O que chama a atenção é o aproveitamento das 800 horas de prática de ensino no trabalho do aluno. Ora, se a unidade formadora não dispõe de um projeto de prática de ensino que integre escolas da rede aos trabalhos acadêmicos, em convênios com escolas previamente definidas e com acompanhamento, mais uma vez estamos minando o sistema de formação teórico-prática dos alunos. Se todo aluno faz a prática de ensino na própria escola para aproveitar as horas que a lei oferece, instalamos, mais uma vez, a caótica situação do individualismo, do espontaneísmo e da prática abandonada. Torna-se inviável acompanhar cada aluno em sua respectiva escola, em locais diferentes, com perspectivas distintas de trabalho.

Para viabilizar um sistema que integre teoria à prática é preciso delimitar escolas, prazos, tipos de práticas e formas de envolvimento de ambos os lados: instituição formadora e escolas que acolhem os alunos. É pre- 
ciso firmar esse vínculo em torno da discussão e da condução do projeto pedagógico da instituição que oferece o espaço para o estágio. Dessa forma, configura-se a parceira, um fluxo de duas mãos, no qual ganham a instituição formadora e a escola que recebe os estagiários, tornando possível o acompanhamento dos alunos e sua supervisão. Essa prática só será possível quando a unidade formadora dispuser de um grande contingente de docentes em tempo integral. Sabemos que a tradição da maioria das instituições de ensino superior particular é, ainda, o contrato de horistas.

Somente o envolvimento dos docentes da unidade formadora nas questões institucionais, na discussão do projeto pedagógico da escola qualifica o trabalho realizado e propicia melhores condições para a formação do aluno.

Outro aspecto que inquieta é a separação entre a formação profissional e a universitária. O curso normal superior fora do contexto universitário deixa de oferecer a diversidade, essencial para a formação docente, não se beneficia do caldo cultural propiciado pelas reflexões sobre as ciências da educação aliadas ao tratamento dos conteúdos, em um espaço que se torna pedagógico, transformando-se em campo fértil de flexibilidade, ações criativas e estratégias de aprendizagem.

\section{Política de formação profissional para a educação infantil}

Pensar em política de formação profissional para a educação infantil requer antes de tudo questionar concepções sobre criança e educação infantil.

O imaginário popular e até dos meios oficiais pouco afeitos às reflexões sobre a criança e a educação infantil referendam, ainda, a perspectiva romântica do século passado, de que para atuar com crianças de 0 a 6 anos basta ser "mocinha, bonita, alegre e que goste de crianças", e a idéia de que não há necessidade de muitas especificações para instalar escolas infantis para os pequenos. Essa parece ser também a forma de pensar que reina entre membros do atual Conselho Nacional de Educação, refletida nas propostas oficiais que se distanciam de uma formação profissional qualificada.

A educação infantil foi inserida na educação básica, portanto, seus profissionais requerem o mesmo tratamento dos outros que nela atuam. É preciso eliminar preconceitos arraigados da tradição brasileira, como o de que 
o profissional que atua com crianças de 0 a 6 anos não requer preparo acurado equivalente ao de seus pares de outros níveis escolares, o que demonstra o desconhecimento da natureza humana e de sua complexidade, especialmente do potencial de desenvolvimento da faixa etária de 0 a 6 anos.

Pensar em uma política de formação profissional para a educação infantil requer, antes de tudo, a garantia de um processo democrático que permita a ascensão na escolaridade, em todos os níveis, e a valorização dessa formação no patamar de outros cursos. Portanto, é preciso pensar também nos leigos, não expulsar os recursos humanos que atuam no sistema.

A diversidade brasileira requer propostas que atendam às especificidades do país. Se o contexto social requer uma formação mais ágil para essa faixa etária, uma política de formação profissional deve estimular o convívio de propostas diferentes, sem que a faina da quantidade obscureça a qualidade dessa formação, sem que a discriminação anule a identidade do profissional.

\section{Notas}

1. Sinopse Estatística da Educação Básica. Censo escolar 98/Instituto Nacional de Estudos e Pesquisa Educacionais. Brasília: O Instituto, 1999, p. 96.

2. Id., ibid., p. 98.

3. Entrevista concedida pelo conselheiro Francisco Aparecido Cordão ao jornal O Estado de S. Paulo, de 10 de agosto de 1999.

4. Ver sobre a questão Bissolli 1999, que destaca as principais questões relacionadas à identidade do curso e contém ampla bibliografia sobre o tema.

5. O Banco de Dados MEC/SESu/Consin/Dain, de cadastro de instituições de ensino superior que oferecem curso de pedagogia, de agosto de 1999, contém informações sobre as IES, endereços, mantenedoras, localidade dos cursos (estados e municípios), tipo de licenciatura (plena, com habilitações), data de funcionamento, credenciamento, entre outras. Para o presente trabalho foram selecionadas as informações pertinentes à educação infantil.

6. Ver a listagem de instituições de ensino superior no anexo.

7. Parecer 115/99 - Diretrizes Gerais para os Institutos Superiores de Educação.

8. Padrões de qualidade para qualificação docente:

conceito $A=$ (excelente) mínimo de $50 \%$ de doutores ou mestres;

conceito $B=($ bom) mínimo de $40 \%$ de doutores ou mestres; 
conceito $\mathrm{C}=$ (regular) mínimo de $20 \%$ de doutores ou mestres ou $30 \%$ de especialistas;

conceito $\mathrm{D}=$ (insuficiente) abaixo do índice do conceito anterior ou sem indicação.

\title{
Professional upbringing policy for child education: Pedagogy and Superior Normal
}

\begin{abstract}
This article presents the policy of teacher education for children in the 1990s as it is established by the Pedagogy Courses and Normal Courses, at superior level. Pedagogy has historically been offering teaching education courses at superior level since the 1930s, showing its engaged political and pedagogical project through linking licentiate degree courses to bachelor degree courses. It has guaranteed, therefore, a better and bigger interaction between the general education and the professional. The Normal Courses at superior level, recreated by the law 9394/96, has brought up some discussion due to the idea of separating the teacher education courses at university from shorter teacher education courses that not only understand caring disassociated from educating but also disqualify the staff of professors responsible for the course.
\end{abstract}

\section{Anexo*}

\section{Relação das Instituições de nível superior com cursos para formar profissionais de Pré-Escola.}

\begin{tabular}{|c|l|c|}
\hline $\begin{array}{l}\text { UCENCIATURA } \\
\text { PRÉ-ESCOLAR }\end{array}$ & \multicolumn{1}{|c|}{ INSTITUIÇĀO SUPERIOR } & DATA \\
\hline 01 & Universidade Federal do Rio de Janeiro (RJ) & 1931 \\
\hline 02 & Universidade Federal do Paraná (PR) & 1938 \\
\hline 03 & Pontifícia Universidade Católica do Rio Grande do Sul - Porto Alegre (RS) & 1942 \\
\hline 04 & Universidade do Sagrado Coraçāo - Baun (SP) & 1954 \\
\hline 05 & Universidade de Sorocaba (SP) & 1955 \\
\hline 06 & Universidade Regional do Noroeste do Estado do Rio Grande do Sul - ljuí (RS) & 1957 \\
\hline 07 & Universidade da Região da Campanha - Bagé (RS) & 1958 \\
\hline 08 & Universidade Estadual Paulista Júlio de Mesquita Filho - Unesp - Marília (SP) & 1959 \\
\hline 09 & Universidade Federal de Uberlândia (MG) & 1960 \\
\hline 10 & Universidade Federal de Santa Catarina - Florianópolis (SC) & 1960 \\
\hline 11 & Fundacão Universidade do Rio Grande - Rio Grande (RS) & 1961 \\
\hline 12 & Universidade Estadual de Ponta Grossa (PR) & 1962 \\
\hline 13 & Universidade Federal do Ceará - Fortaleza (CE) & 1963 \\
\hline 14 & Universidade do Vale do Itajaí (SC) & 1965 \\
\hline
\end{tabular}

* A relação completa das instituições de ensino superior que dispõem de cursos destinados à formação profissional para a educação infantil poderá incentivar estudos nesse campo. 


\begin{tabular}{|c|c|c|}
\hline 15 & Faculdade de Filosofia, Ciências e Letras de Santo André (SP) & 1966 \\
\hline 16 & Faculdade de Filosofia Ciências e Letras de Jahu (SP) & 1966 \\
\hline 17 & Universidade de Mogi das Cruzes (SP) & 1966 \\
\hline 18 & Faculdade de Filosofia Santa Dorotéia - Nova Friburgo (RN) & 1967 \\
\hline 19 & Universidade Estadual da Paraiba - Campina Grande (PB) & 1969 \\
\hline 20 & Universidade de Santa Cruz do Sul (RS) & 1969 \\
\hline 21 & Universidade Federal do Mato Grosso - Cuiabá (MT) & 1970 \\
\hline 22 & Universidade Federal do Mato Grosso do Sul - Corumbá (MS) & 1970 \\
\hline 23 & Universidade de Ribeirão Preto (SP) & 1970 \\
\hline 24 & Universidade Estadual de Campinas (SP) ${ }^{\star}$ & 1971 \\
\hline 25 & Pontifícia Universidade Católica de Sāo Paulo (SP) & 1971 \\
\hline 26 & Universidade Paulista (SP) & 1972 \\
\hline 27 & Centro de Estudos Superiores de Londrina (PR) & 1972 \\
\hline 28 & Universidade Federal do Piauí -Teresina (PI) & 1973 \\
\hline 29 & Universidade Regional do Noroeste do Estado do Rio Grande do Sul - ljuí (RS) & 1973 \\
\hline 30 & Faculdade de Educação de Joinvile (SC) & 1973 \\
\hline 31 & Universidade Estadual de Maringá (PR) & 1973 \\
\hline 32 & Universidade do Estácio de Sá - Rio de Janeiro (RJ) & 1974 \\
\hline 33 & Universidade Veiga de Almeida - Rio de Janeiro (RJ) & 1974 \\
\hline 34 & Faculdade Pio Décimo - Aracaju (SE) & 1976 \\
\hline 35 & Universidade Regional do Noroeste do Estado do Rio Grande do Sul - Santa Rosa (RS) & 1976 \\
\hline 36 & Universidade da Amazônia - Belém (PA) & 1980 \\
\hline 37 & Universidade Metodista de Piracicaba (SP) ${ }^{\star}$ & 1981 \\
\hline 38 & Universidade Federal do Mato Grosso do Sul -Campo Grande (MS) & 1983 \\
\hline 39 & Universidade Federal do Mato Grosso do Sul - Dourados (MS) & 1983 \\
\hline 40 & Universidade Federal de Santa Maria (RS) & 1984 \\
\hline 41 & Universidade do Estado da Bahia - Salvador (BA) & 1985 \\
\hline 42 & Universidade Estadual de Maringá (PR) & 1986 \\
\hline 43 & Universidade Estadual de Feira de Santana (BA) & 1987 \\
\hline 44 & Universidade Luterana do Brasil - Canoas (RS) & 1988 \\
\hline 45 & Universidade Estadual Júlio de Mesquita Filho - Unesp - Presidente Prudente (SP) & 1988 \\
\hline 46 & Universidade Estadual Júlio de Mesquita Filho - Unesp - Rio Claro (SP) & 1988 \\
\hline 47 & Universidade Estadual Júlio de Mesquita Filho - Unesp - Marília (SP) & 1959 \\
\hline 48 & Centro de Ensino Superior de Jaraguá do Sul (SC) & 1988 \\
\hline 49 & Fundaçăo Universidade do Rio Grande (RS) & 1989 \\
\hline 50 & Universidade do Vale do Itajaí - Tijucas (SC) & 1990 \\
\hline 51 & Faculdade de Filosofia, Ciências e Letras de Itumbiara (GO) & 1990 \\
\hline 52 & Universidade Estadual do Rio de Janeiro (R.J) & 1991 \\
\hline 53 & Universidade da Região da Campanha - Dom Pedrito (RS) & 1991 \\
\hline 54 & Universidade Estadual da Bahia - Teixeira de Freitas (BA) & 1992 \\
\hline 55 & Universidade Federal Fluminense - Angra dos Reis (RJ) & 1992 \\
\hline 56 & Universidade do Passo Fundo - Casca (RS) & 1993 \\
\hline 57 & $\begin{array}{l}\text { Universidade Regional do Noroeste do Estado do Rio Grande do Sul - Três Passos } \\
\text { (RS) }\end{array}$ & 1993 \\
\hline 58 & Universidade Estadual do Oeste do Paraná - Francisco Beltrão (PR) & 1994 \\
\hline 59 & Universidade do Passo Fundo - Carazinho (RS) & 1995 \\
\hline 60 & Universidade do Passo Fundo - Passo Fundo (RS) & 1995 \\
\hline 61 & Universide Paulista - Campinas (SP) & 1996 \\
\hline 62 & Faculdades Integradas Maria Thereza - Niterói - (RJ) & 1996 \\
\hline 63 & Universidade de Uberaba - Uberaba (MG) & 1997 \\
\hline 64 & Faculdade de Educaçăo de Costa Rica (MS) & 1999 \\
\hline 65 & Faculdade de Pedagogia - Nova Andradina (MS) & 1999 \\
\hline 66 & Instituto de Ensino Superior de Cotia (SP) & 1999 \\
\hline 67 & Faculdade Dom Bosco - Cascavel (PR) & 1999 \\
\hline 68 & Faculdade de Ciências da Educação de Indaial (SC) & 1999 \\
\hline 69 & Universidade Federal do Mato Grosso do Sul - Coxim (MS) & s/d \\
\hline 70 & Universidade Federal do Mato Grosso do Sul - Jardim (MS) & $s / d$ \\
\hline 71 & Fundacāo Universidade do Rio Grande - Santa Vitória do Palmar (RS) & $s / d$ \\
\hline 72 & Universidade Federal do Rio Grande do Sul - Porto Alegre (RS) & $s / d$ \\
\hline 73 & Faculdades Unidas de Varzea Grande (MT) & $s / d$ \\
\hline 74 & União de Escolas Superiores de Funeso - Olinda (PE) & $s / d$ \\
\hline 75 & Faculdade Italo-Brasileira (SP) & $s / d$ \\
\hline
\end{tabular}




\begin{tabular}{|l|l|c|}
\hline 76 & Faculdade Albert Einstein (SP) & $\mathrm{s} / \mathrm{d}$ \\
\hline 77 & Faculdade Morumbi Sul (SP) & $\mathrm{s} / \mathrm{d}$ \\
\hline 78 & Faculdade de Ciências Gerenciais de Brasilia - Brasilia (DF) & $\mathrm{s} / \mathrm{d}$ \\
\hline
\end{tabular}

* Essas instituições aparecem duas vezes na listagem, com as mesmas informações. Foi eliminada a repetição.

\begin{tabular}{|c|c|c|}
\hline $\begin{array}{l}\text { UCENCIATURA } \\
\text { MAGISTÉRIO } \\
\text { DO PRÉ-ESCOLAR } \\
4^{y} \text { SÉRIE DO E.F. }\end{array}$ & INSTITUIÇÃO SUPERIOR & DATA \\
\hline 01 & Universidade Católica do Paraná - Cunitiba (PR) & 1952 \\
\hline 02 & Universidade Católica de Pelotas (RS) & 1956 \\
\hline 03 & Universidade Regional do Noroeste do Estado do Rio Grande do Sul - ljuí (RS) & 1957 \\
\hline 04 & Universidade Estadual de Ponta Grossa (PR) & 1962 \\
\hline 05 & Universidade de Brasilia (DF) & 1962 \\
\hline 06 & Universidade Regional do Noroeste do Estado do Rio Grande do Sul - ljuí (RS) & 1973 \\
\hline 07 & Universidade da Região da Campanha - Alegrete (RS) & 1974 \\
\hline 08 & Universidade da Amazônia - Belém (PA) & 1980 \\
\hline 09 & Universidade da Região da Campanha - São Gabriel (RS) & 1990 \\
\hline 10 & Universidade Estadual de Mato Grosso - Sinop (MT) & 1990 \\
\hline 11 & Universidade Regional de Blumenau - Blumenau (SC) & 1990 \\
\hline 12 & Universidade Regional de Blumenau - Rio do Sul (SC) & 1990 \\
\hline 13 & Universidade Regional de Blumenau - Brusque (SC) & 1992 \\
\hline 14 & Universidade ( federal) de Brasilia (DF) & 1993 \\
\hline 15 & Universidade Estadual do Mato Grosso do Sul - Ivinhema (MS) & 1995 \\
\hline 16 & Universidade da Regiāo de Joinville - Joinville (SC) ${ }^{\star}$ & 1995 \\
\hline 17 & Universidade Regional de Blumenau - Ibirama (SC) & 1995 \\
\hline 18 & Universidade Regional de Blumenau - Rio do Sul (SC) & 1995 \\
\hline 19 & Universidade da Cruz Alta (RS) & 1995 \\
\hline 20 & Universidade Regional de Blumenau - Criciuma (SC) & 1996 \\
\hline 21 & Universidade Regional de Blumenau - Brusque (SC) & 1996 \\
\hline 22 & Universidade Regional de Blumenau - Timbo (SC) & 1996 \\
\hline 23 & Universidade Regional de Blumenau - Lages (SC) & 1996 \\
\hline 24 & Universidade Estadual de Mato Grosso do Sul - Maracaju (MS) & 1997 \\
\hline 25 & Universidade do Planalto Catarinense (em acompanhamento) Sāo Joaquim (SC) & 1998 \\
\hline 26 & Faculdade de Educação de Colorado do Oeste (RO) & 1998 \\
\hline 27 & Faculdade Juscelino Kubitschek - Brasilia (DF) & 1999 \\
\hline 28 & Faculdade Dom Bosco - Cascavel (PR) & 1999 \\
\hline 29 & Instituto de Ensino Superior da Funlec - Campo Grande (MS) & $s / d$ \\
\hline 30 & Faculdade para Executivos - Natal (RN) & $s / d$ \\
\hline 31 & Faculdade Nilton Lins - Manaus (AM) & $s / d$ \\
\hline 32 & Universidade Cândido Mendes - Rio de Janeiro (RV) & $s / d$ \\
\hline 33 & Faculdade de Educacão de Osvaldo Cruz (SP) & s/d \\
\hline 34 & Faculdades Integradas de São Paulo (SP) & $s / d$ \\
\hline
\end{tabular}

* Essas instituições aparecem duas vezes na listagem, com as mesmas informações. Foi eliminada a repetição.

\section{Bibliografia}

BIARNÉS, Jean. Universalité, diversité, sujet dans l'espace pédagogique. Paris: L'Harmattan, 1999. 
BRASIL/MEC/CNE. Parecer CP 115/99, aprovado em 10/08/99, sobre Diretrizes Gerais para os Institutos Superiores de Educação.

BRASIL/MEC/SESu/Consin/Dain. Cadastro de instituições de Ensino Superior, 1999.

BRASIL/MEC/SESu. "Diretrizes do curso de pedagogia". Maio 1999.

BRASIL/MEC/Inep. SINOPSE ESTATÍSTICA DA EDUCAÇÃO BÁSICA. Censo escolar 98. Brasília: O Instituto, 1999.

BRASIL/PR. Lei no 9.394, de 20/12/1996. Estabelece as diretrizes e bases da educação nacional. Diário Oficial da União. Brasília: Gráfica do Senado, ano CXXXIV, nl. 248, 23/12/96, pp. 27833-27841.

CHAMLIAN, Helena Coharik. "Currículo do curso de pedagogia na USP". Revista da Faculdade de Educação no 2, v. 22. São Paulo, jul./dez. 1996, pp. 131-157.

KISHIMOTO, T.M. A pré-escola em São Paulo. São Paulo: Loyola, 1988.

O ESTADO DE S. PAULO, 20 de agosto de 1999.

SILVA, Carmem Silvia Bissolli da. "Curso de pedagogia no Brasil: História e identidade". Dissertação de mestrado. Marília: Unesp, 1999. 